\title{
Move or perish? Sticky mobilities in the Swiss academic context
}

\author{
Marie Sautier ${ }^{1,2}$ (DD \\ Published online: 29 May 2021 \\ (C) The Author(s) 2021
}

\begin{abstract}
This article uses a context of increasing institutional demand to be geographically mobile to examine how early-career researchers move across borders. I explore the case of Swiss academia, a particularly competitive and attractive environment with the highest levels of inbound and outbound mobility in Europe. In line with the aims of the European Research Area, an EU programme created in 2000 to foster a pan-European academic labour market, Switzerland funds scientific mobility and promotes extended research trips abroad as tools to boost collaboration and research excellence. Therefore, Swiss institutions have valued mobility for professional and personal development. In the meantime, they have raised concerns about female academics not being mobile and the potential consequences of their local family ties on career inequalities. In this study, I explore how early-career researchers experience mobility and how their personal accounts challenge institutional definitions of being mobile or immobile. I draw on a qualitative analysis of 65 semi-structured interviews conducted for two EU research projects on early-career academics from various backgrounds. I show how empirical data question the traditional - and often gendered-mobile/immobile dichotomy. I also highlight how mobility practices are normalised by the interviewees. Moreover, using the concept of stickiness, I describe a subtle range of sticky-to-stretchy mobility experiences influenced by both structural and individual factors. Finally, through the figure of the geoccasional worker, I question romanticised visions of mobility and stress the need to reconsider mobility as a (gendered) precarity issue rather than as a female problem.
\end{abstract}

Keywords Academic mobility · Sticky mobility · Early-career researchers · Casualisation · Precarity $\cdot$ Postdoctorate $\cdot$ Work-life balance

Marie Sautier

marie.sautier@unil.ch

1 University of Lausanne, NCCR-LIVES, Lausanne, Switzerland

2 Sciences Po Paris, CSO, Paris, France 


\section{Introduction}

In today's ever-escalating international competition for academic talent, geographical mobility has increasingly appeared as a salient component of academic careers in the Global North (Jepsen et al., 2014). The EU has defined a pan-European academic labour market as a priority for the European Research Area (European Commission, 2012). By 2016, most European countries had already adopted an internationalisation strategy at the national level (European Commission, 2017). However, the internationalisation of the academic workforce varies considerably across countries (European Parliament, 2015; Geuna, 2015). Switzerland represents a particularly competitive and attractive academic environment (Bataille et al., 2017); more than half of its academic workforce comes from abroad (Franzoni et al., 2012). That is two to three times more than its neighbouring countries. Conversely, the Swiss system regularly heads the list of the most internationalised European countries in terms of outbound academic mobility (European Commission, 2016; Franzoni et al., 2012).

The EU sees mobility as a sign of research excellence (European Commission, 2012) but also as a tool to promote personal development and employability and an instrument for increasing collaboration across academic systems (Bologna Follow-Up Group, 2009). Against this backdrop, academic mobility has been largely described and studied through the lens of a positive force for researchers and their institutions (Marginson \& van der Wende, 2009).

However, a few studies have also expressed reservations concerning what they describe as a romanticised or fetishised vision of mobility (Robertson, 2010). This paper contributes to building a more balanced perspective by questioning traditional epistemological framings of academic mobility via an analysis of the complexity of individuals' experiences.

I focus on the context of Switzerland, one of the most internationalised academic markets worldwide. The Swiss academic system is characterised not only by a high level of inbound mobility and international recruitment but also by the incentive scheme and the financial support for the outbound mobility of early-career researchers who have completed a $\mathrm{PhD}$ in Switzerland. Swiss-educated researchers are commonly encouraged to go abroad for one or several postdocs after their $\mathrm{PhD}$. Institutional discourses advertise specific forms of academic mobility as both a mandatory step in an academic career and as a fulfilling experience at the personal and professional levels (Sautier, 2021).

In line with some of the categories used in academic mobility studies (Geuna, 2015), EU indicators and institutional discourses commonly have conceptualised mobility behaviours through the binary opposition of mobile and immobile (Directorate General for Research and Innovation, 2018). However, I highlight the need to develop alternative analytical tools to explore individuals' experiences of mobility in ever-interlinked internationalised contexts. I explore how early-career researchers experience mobility through the qualitative analysis of 65 interviews conducted within two EU research projects. From that basis, I show how empirical data call in question the traditional-and often gendered - being mobile versus not being mobile dichotomy. I highlight how mobility behaviours have become a normative horizon among Swiss-based early-career researchers and use the concept of stickiness to describe a subtle range of mobility's experiences. I examine how such experiences may be analytically considered on a continuum between sticky and stretchy and show how they are intertwined with personal and social characteristics on one hand and institutional and systemic factors on the other hand. Through the figure of the geoccasional worker, I finally question romanticised visions of mobility and point out the necessity to consider - for a large part - the mobility problem as a precarity issue rather than a women's one. 
To address these themes, this paper first dives into the epistemological questions at stake (I). Through analysis and literature review, I present the different layered components that contribute to the mixed reality of academic mobility. In the continuation, with all concepts introduced, I explain the methodology and resources I chose for the article (II). Then, I produce four in-depth case studies that offer contrasting, representative aspects of academic mobility (III). Finally, I propose a discussion (IV) before concluding this paper.

\section{Unpacking academic mobility with epistemological framings: an exploration from the highly internationalised context of Switzerland}

The geographical mobility of students and scholars across European borders is not a new phenomenon (Fernandez-Zubieta et al., 2015). As epitomised by Erasmus of Rotterdam - who obtained a $\mathrm{PhD}$ in Torino then lectured for a few years in Cambridge and Leuven before settling down in Basel (De Ridder-Symoens, 1996) - academics have been moving between institutions for centuries.

However, the mobility of scholars has surged significantly in the past decades (Geuna, 2015), along with two major changes that are transforming contemporary universities across Europe: the massification of higher education institutions and their internationalisation. In this paper, I focus on the highly internationalised case of Swiss academia, a competitive and attractive academic environment (Bataille et al., 2017). The Swiss system regularly leads the list of the most internationalised European countries, with top-level indicators in both inbound and outbound academic mobility (European Commission, 2016; Franzoni et al., 2012).

In the next sections, I highlight how specific epistemologies have framed institutional categories of academic mobility. In particular, I underline in what ways Swiss institutions tend to portray mobility as a positive force and as a dualistic, normative category. I scrutinise how this epistemological framing of the circulation of scholars is commonly at play in academic mobility studies, opposing and hierarchising the mobile and the immobile. Furthermore, I question one of these dichotomies' popular embodiments: the - gendered - figure of the immobile academic. Then, I shed some light on a phenomenon that runs parallel to the internationalisation of academic careers and that is intertwined with its complexity: the casualisation of early-career research positions. Finally, I offer to use the alternative concept of stickiness, the nuances and flexibility of which enable all aforementioned components to be encompassed in the understanding framework, to explore the mobility phenomenon in analytical, rather than institutional, terms.

\section{From the Peregrinate Academicus to the Erasmus era: academic mobility as a positive force}

The notion of scholars' international mobility is far from echoing only the physical phenomenon of moving across spaces. In the European context, the concept reflects a set of traditions and narratives praising intellectual collaboration, excellence and scientific competitiveness (European Commission, 2012). However, it also extols the virtues of employability and personal self-realisation (Bologna Follow-Up Group, 2009).

As the embodiment of the historical figure of the peregrinate academicus - a (generally privileged) scholar who travels across European universities to accumulate knowledge and experience-Erasmus has given his name to two emblematic EU exchange programmes. Not only have they played a major role in fostering the circulation of students and researchers in 
the last decades (Engel, 2010), but they also became part, through artistic productions, of a popular imaginary association of scholarly exchanges with a sense of discovery, openmindedness and self-realisation (Béguin, 2004).

Switzerland is a partner of the European Research Area and is characterised by the particularly high level of internationalisation of its workforce. Internationalisation policies are formally part of the federal strategy to sustain the competitiveness of the Swiss economy and its research system (Conseil d'Etat, 2010; Swiss National Science Foundation, 2015). Funding agencies and universities actively support mobility as a profitable instrument for researchers and their institutions (Rectors' Conference of the Swiss Universities, 2014). The portrayal of academic circulation as both an asset and a virtue is not yet specific to Switzerland. In line with EU recommendations, most European countries have developed some programmes to foster the circulation of the academic workforce across borders (Appelt et al., 2015; European Commission, 2017). Against this backdrop, academic mobility has been largely described and studied through the epistemological lens of a positive force for European researchers and their institutions (Marginson \& van der Wende, 2009).

Nonetheless, a few studies have also provided reservations regarding what they describe as a romanticised or fetishised vision of mobility (Robertson, 2010). Some authors have called for a more accurate understanding of the "darker side of an international academic career" (Richardson \& Zikic, 2007) for researchers and their institutions.

In line with recent studies that pointed out the different facets of mobility (Morley et al., 2018; O'Keefe \& Courtois, 2019; Pustelnikovaite, 2020; Schaer, 2021), I respond to the call to question the representation of academic mobility as a "universal good", and I depict the ambivalent nature of academic mobility through individuals' life experiences.

\section{To be or not to be academically mobile: questioning dualistic and normative interpretations of academic mobility}

In a recent report, the EU highlighted the difficulty of producing comparative studies on the mobility of researchers across its countries and their partners, pointing out that higher education authorities use different definitions to distinguish those who are mobile from those who are not (European Commission, EACEA, \& Eurydice, 2018). Such considerations underline the variety of meanings attached to "international mobility" or "academic mobility" in diverse contexts. They also reveal the popularity that dualist understandings of mobility enjoy, both in European research institutions and in the scientific literature. Calculating a mobility rate, or an international experience rate, and quantifying the mobile part of a given population brings out, in contrast, the nonmobile part of the same population.

This epistemological, dualistic framing of academic mobility prevails in various Swiss institutional discourses (Rectors' Conference of the Swiss Universities, 2014), guidelines or instruments that explicitly or implicitly define mobility by distinguishing — and valuing - the mobile researchers over the nonmobile ones.

For example, the Swiss National Foundation (SNF), the main public funding agency for research, has participated in defining "academic mobility" as a specific set of practices in the last 20 years (Sautier, 2021): On one hand, the SNF has fostered academic mobility by channelling massive financial resources ${ }^{1}$ to support, in particular, a normative and prescriptive

\footnotetext{
${ }^{1}$ Through the massive funding of postdoc scholarships abroad in all fields, the SNF has created a pool of shortterm opportunities that contribute to shaping the paths of research careers.
} 
mobility practice that fits the following criteria: a one-year minimum postdoctoral stay in a foreign research institution ${ }^{2}$. On the other hand, the SNF has standardised, in the last decades, such particular experience of "being mobile" abroad as a formal requirement to apply for its most advanced grants (Excellenzia grants) in all fields. Both of these phenomena contribute to moulding specific definitions of academic mobility across Swiss institutions and disciplinary fields. In addition, via its funding and requirements, the SNF's influence shapes scholars' perspectives, as it has socialised early-career researchers with the prescriptive idea that such mobility is a box to tick to advance in their careers (Sautier, 2021). "Academic mobility" may thus not be understood solely as a phenomenon related to the circulation of researchers across spaces but also as a normative dualistic category, embedded in particular institutional contexts and with which early-career researchers must comply to be deemed worthy.

\section{Academic mobility: a women's problem?}

Numerous studies focusing on the circulation of academic workers and its determinants have adopted both epistemologically and methodologically a dualistic and normative framing of the mobility phenomenon. Although the choice itself is rarely reflected on as a topic of research or detailed explicitly in the methodology section, it has serious consequences as it may strengthen particular realities for groups that it labels "mobile" or as "immobile". In particular, studies about mobility patterns of female and male researchers may run the risk of reinforcing the naturalised gendered representations of mobility at play in institutional settings, even while being critical of the potentially discriminatory effect of the mobility requirement.

Though Swiss institutional discourses barely question the value of academic mobility as a "universal good" (Morley et al., 2018), they occasionally — and somewhat paradoxicallyportray mobility as a potential problem for specific groups of researchers and particularly as a "women problem" (Sautier, 2021). These institutional interpretation patterns include associating men with mobility and women with immobility, which generally goes hand in hand with the use of stereotypical (heteronormative) figures. They consider that female researchers (probably) have a hard time articulating their domestic lives with the expectation to be mobile, they (may) have children for whom they are the main caregivers, they (probably) live with a (male) partner who works full-time and is dedicated to his own (high-profile) career and so on.

The institutional discourses on the "mobility problem" thus usually refer to two implicit understanding frameworks: Their understanding of mobility is not only a women's problem but more precisely is a work/private life balance issue.

I argue that these two framings pose several problems. The first framing tends to naturalise the mobility or immobility of women despite the lack of scientific consensus over this supposed mobility or immobility. Indeed, scientific evidence supports the idea that male and female mobility patterns vary greatly depending on the national environment (Goastellec, 2016) and therefore is not universal. For example, even within a heterogeneous Western European context, results of an EU study published in 2015 showed large gaps between male and female mobility in the UK and in France but no significant difference between Swissbased female and male researchers - both being highly mobile.

\footnotetext{
${ }^{2}$ In this contribution, I use the terms "academic mobility" and "being mobile" with quotation marks when they refer to this institutional - narrow-definition of mobility, by opposition to a broader phenomenon (such as attending conferences, travelling for archive work or fieldwork, visiting a foreign lab for a few weeks, etc.).
} 
The second problem identified lays in that the second layer of framing, that is, the worklife balance issue, fuels and circles back to the first framing of mobility as a women's issue, as the work-life theme is still mostly perceived as a women's problem. Because it maintains the analysis in a traditional mind-set, it also impedes additional understanding frameworks of other or newer phenomena that emerge, such as contemporary academic career transformations, and their casualisation. In a later section of the paper, I respond to this problem by introducing the figure of the geoccasional worker as new concept that challenges romanticised visions of mobility. It flags the need to consider the mobility problem as a precarity problem embedded in the current transformation of academic environments rather than as a female problem.

\section{Mobility and the casualisation of academic careers: surviving Swiss academia}

The Swiss academic market combines a high level of international hiring with a low level of employment security (Afonso, 2016). As in Germany, the Swiss academic system can be characterised by what Enders and Musselin (2008) defined a "survivor model": After finishing their PhDs, aspiring academics must go through various trials to provide evidence of their talents and wait many years to obtain a permanent position. Only those who manage to overcome this long period of selection and competition have the chance to survive.

As shown by Bataille et al. (2017), the competition for permanent professorships has intensified in Switzerland over the past 25 years: In 1980, there were four fixed-term (assistantships or scientific collaborator) positions for every full professorship. By 2014, this figure had increased by $100 \%$ (from 1:4 to 1:8). Access to a tenured position rarely happens before the age of 40 , and postdoctoral researchers commonly face the challenge of surviving a probationary period of 8-10 years, characterised by a succession of fixed-term positionsoften in different locations and countries - and a high level of uncertainty (Le Feuvre et al., 2020).

Early-career researchers working in the Swiss context are thus extensively exposed to two phenomena - the casualisation of careers and their internationalisation - that appear in a number of contemporary academic systems worldwide, in varying degrees. On one hand, the lasting influence of the survivor model on the current structure of the Swiss academic labour market makes young researchers particularly vulnerable to an extended period of precariousness and short-term employment contracts; On the other hand, both the institutional discourses and coercive measures fostering academic mobility tend to dissuade young Swiss researchers from considering a succession of short-term contracts in the same location (Bataille \& Sautier, 2019).

Hence, these phenomena - the casualisation of careers and their internationalisation - have an impact not only on the professional and academic trajectories of early-career researchers, but also on their personal lives and the interaction between these spheres. This article contributes to providing an in-depth understanding of how these phenomena affect the lives and career pathways of early-career scholars during a period ${ }^{3}$ that involves multiple commitments, such as improving one's academic CV, applying for stable jobs, establishing a relationship or having a child.

\footnotetext{
${ }^{3}$ Around $70 \%$ of researchers who earn a $\mathrm{PhD}$ in the Swiss context graduate after the age of 30 years (Office Fédéral de la Statistique, 2018).
} 


\section{Mobility stickiness: an alternative tool for exploring the circulation of scholars}

In the following paragraph, I suggest setting aside these mobility understanding frameworks built on a positive, dualist, normative and sexist epistemology to scrutinise this phenomenon through the concept of stickiness instead.

I build on the tradition of anthropologists and social scientists to distinguish between the emic (categories used by and within the studied group to classify the world) and etic (categories built from an analytical viewpoint by the outsider researcher) when studying a social phenomenon (Moussaoui, 2012).

Rather than distinguishing who is mobile and who is not, I explore how early-career researchers experience mobility and in what ways their experience reproduces or challenges institutional - that is, emic - dualistic definitions of being mobile versus not being mobile. I answer Tzanakou and Henderson's (2018) call to use the innovative concept of stickiness to describe and highlight a subtle range of mobility experiences. Tzanakou and Henderson pointed out how mobility may be "considered 'sticky' when an academic relocates to a new country context but in some way retains an imprint of the previous context . . or when the mobility imperative is countered with personal circumstances".

I build on Ackers' (2005) observation that mobility tends to "become stickier over the life course" to consider mobility mainly as a dynamic experience - shaped by one's personal and professional environments - rather than as an individual plain characteristic. The choice to define mobility stickiness as a continuum allows me to make visible how people move and what makes this experience more or less sticky or stretchy, with potential effects on their career paths.

This definition of stickiness also adopts Henderson's (2020) definition. She emphasised,

When any academic travels, a sticky contact zone is revealed between the academic and their home life which can be explored in terms of both practical and emotional stickiness. . . . the stickiness can be imagined as akin to chewing gum, which remains on both surfaces when pulled apart (e.g. shoe and pavement), with sticky stretchy strings trailing between.

Following Henderson's metaphors, I envision mobility stickiness as the extent to which the mobile person remains deeply attached and pulls from their former locations by a series of strings and dependencies that constrain their actions. Although the strings are binding material, the social ties always exist to some extent between two locations and may be experienced as constraining at the far end of the sticky spectrum or as looser - or stretchier - at the opposite endpoint.

\section{Methodology}

To address these research questions, I draw on 65 semi-structured interviews that were conducted within two European projects, those of GARCIA ${ }^{4}(2014-2017)$ and POCARIM 5 (2012-2014), featuring postdoctoral researchers of various nationalities, scientific fields,

\footnotetext{
${ }^{4}$ Gendering Academy and Research: Combating Inequalities and Asymmetries, http://garciaproject.eu/.

${ }^{5}$ Mapping the Population, Careers, Mobilities, and Impacts of Advanced Research Degree Graduates in the Social Sciences and Humanities.
} 
genders and family arrangements working in the Swiss academic context. The GARCIA project was aimed at analysing the precise mechanisms behind gender inequalities in early academic careers. The POCARIM project mapped the careers of $\mathrm{PhD}$ graduates in the social sciences and humanities. The fact that the two sets of interviews (25 interviews in the POCARIM project, 40 in the GARCIA project) shared numerous similarities allowed me to address my research questions via a secondary analysis of the data. First, both sets were based on semi-structured interviews that allowed individuals to talk in depth about their careers and personal trajectories, their representations of academia and how they made their choices. Second, in both data sets, the interviewees were working or had been working previously at a Swiss university. Finally, both project samples covered a diverse postdoctoral population with regard to their genders, trajectories in or out of academia, and positions at the time of the interview. I must flag here that all the relationships mentioned during the interviews were heterosexual. The interviewees' characteristics (nationality, gender, professional and family situation, disciplinary field) are presented in Fig. 1.

I conducted a thematic analysis of the data (Bernela \& Milard, 2016; Hinder \& Greehalgh, 2012) using NVivo for each interview and identifying key issues and stories related to academic mobility. I iteratively refined analytic categories along this process (Glaser \& Strauss, 1967), paying particular attention not only to the interviewees' objective geographical trajectories but also to their subjective attitudes towards international mobility. Jointly scrutinising these two dimensions resulted in a richer and a more subtle framework for analysing how individuals manage institutional incentives to be mobile.

In the next section, I present four detailed cases to focus on academic mobility at a microlevel. I used pseudonyms to present individuals' trajectories and changed some details to
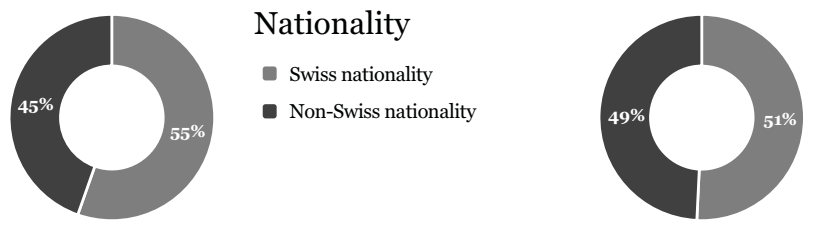

Sex

- Female

- Male



$$
\begin{aligned}
& \text { Employment } \\
& \text { Working in academia } \\
& \text { Working outside academia } \\
& \text { Unknown }
\end{aligned}
$$

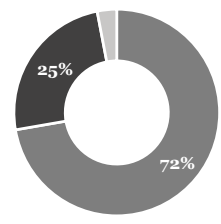

\section{Marital Status \\ - In a relationship or married \\ - Single \\ Unknown}

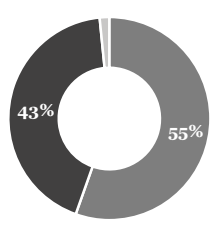

\section{Family Situation}

- Has children

- Does not have children

Unknown

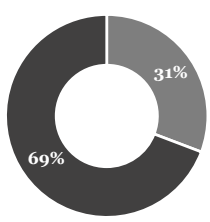

Discipline

- PhD in Life Sciences

(Biology, Medicine,

Neuroscience, Biochemistry...)

- $\mathrm{PhD}$ in Social Sciences and Humanities (Sociology, Anthropology, Politics, History, Psychology...v)

Fig. 1 Interviewees' characteristics in terms of nationality, gender, professional and family situation, disciplinary field. $45 \%$ of the participants were non-Swiss citizens at the time of the interviews 
protect their anonymity. The selection of a few case studies applied the following process: First, I selected a dozen emblematic cases covering the key issues that were redundant across the interviews. Secondly, I paired cases that gave complementary insights to address the research question. Simultaneously, I paid attention to the diversity of the interviewees' personal characteristics, including four very diverse researchers, in terms of nationality, gender, professional and family situation, and disciplinary field. This methodology allowed me to cover a wider variety of situations and illustrate the complexity of the logics at stake in ways that sometimes challenge conventional representations. ${ }^{6}$

I then discuss how these case studies enabled me to deconstruct some of the frameworks and narratives traditionally used to describe academic mobility. Finally, using the concept of stickiness allowed me to describe in more depth some of the frictions that researchers experience while moving across places.

A majority of the interviewees who conducted their $\mathrm{PhD}$ studies in Switzerland (men and women alike and from very diverse disciplinary fields) directly associated their decision to undertake an extended stay abroad with the existence of an implicit or explicit requirement in their field. Academic mobility appeared as a career norm, the weight of which in the researchers' decision-making was reinforced by their perceptions of an academic career as being both precarious and highly competitive. Qualitative data provide a clearer insight on the extent to which the characteristics of the institutional and national environments, on one hand, and private circumstances, on the other, heavily shape professional decisions and sticky or stretchy experiences of mobility across borders, both inside or outside of academia.

\section{Moving across borders: four portraits of academic mobility}

\section{Aline: "If You Don't Go Abroad, You Will Never Get a Position"-a sticky experience of forced migration}

Aline, a Swiss citizen, holds a $\mathrm{PhD}$ in psychology. She is in her thirties and has recently quit the academic world, following burnout. Aline explains her withdrawal from an academic career by the constraints of mobility (whether long or short repetitive stays) and the exhaustion it generated, against a backdrop of high tensions between her professional and private lives.

Aline's academic vocation started in Switzerland with the completion of her PhD studies. She gave birth to two children during her doctorate studies. Her academic job provided her with flexible working hours, unlike her husband's manager position. This situation tends to strengthen the traditional division of housework and parenting tasks within a couple. In the absence of other family support she could rely on, she often had to cancel day work to take care of her daughter, and she would try to catch up her with her workload at night. She slowly became exhausted by what she described as "an infernal cycle":

When a kid is sick, [my husband tells me,] "Well, I can't cancel a 30-person conference" [laughs] . . . so [I reply,] "Hmm, well, go to work. I can still work tonight" [laughs], and that's it. . . . so anyway, it was me who assumed all of the family load.

\footnotetext{
${ }^{6}$ For example, I combined two case studies that were emblematic of common gendered mobility arrangements among the sample with two additional case studies that challenged such conventional arrangements.
} 
At the end of her thesis, Aline left Switzerland to complete a one-year postdoctorate position in England, following her supervisor's pressing advice and despite her own reluctance. However, her mobility was a single-handed move:

My husband had a stable job, finally including some responsibilities, so he was not going to quit his work to spend barely one year in Oxford. And we had a spot at the nursery here - everything was settled, so we did not want to move out for . . . well . . . just for a year, knowing that it's [a Swiss National Science Foundation] post-doc. It wasn't a position that I would have on site.

Aline rents an apartment in Oxford and goes back and forth several times per month between Oxford and Geneva, where she continues to assume part of the childcare. The feeling that an academic career is ever demanding and requires one "to do even more" in a context already shaped by efforts, concessions and struggles hastened her withdrawal from the academic path shortly before the end of her contract:

There was a whole research team, a bit multicultural, that had planned to meet like . . Hmm, in September in Italy, in January in Germany, in March . . . in Brazil [etc.], and clearly, if you're not there, you're not included in the [final publication] . . . . I was like, "Hmm ... so I already cannot even find time to properly do my work [and] I am already flying back and forth to Oxford". And I told myself, "This is not going to work for me". [laughs] . . . and after that, I couldn't even get out of bed during the weekend. . . . It was really ... I was bedridden and then, well, it was over. . . . [I realized during this meeting]: "It's completely beyond my reach". I didn't have the means to fund all of that and to work; in addition, I was already feeling like fighting".

Aline lamented that the working environment encouraged the idea that "everything is up you, and that you will never give enough anyway". She provided a bitter narrative regarding her professional burnout and the dictates that burdened her life abroad.

At the very moment when I quit, I could have had a [new fixed-term] job at my home university . . . but in fact, I had already blown all of my eagerness to pursue my career. It happened too late. ... It's the fact that I was told at the end of my thesis, "Now, you're going to get out of here, okay? Because otherwise your [diploma is] worth nothing".

Now a stay-at-home mother, Aline plans on opening a small business locally, unrelated to her professional background.

Aline's experience epitomises a case of extreme stickiness with several combined components. She considered her departure abroad as a forced displacement rather than as a deliberate choice, in a context of professional casualisation. It started with an institutional injunction ("You're going to get out of here . . ; otherwise, your [diploma is] worth nothing"), which made Aline believe that staying would discredit her on the academic job market. Against that backdrop, Aline organised her mobility in such way that it resembled more of an experience of long-distance commuting - with the financial, time and organisation costs it includes - rather than as a relocation. The gendered division of labour within the couple participated in making the mobility sticky: the physical distancing did not come with a distancing from the household or mental workloads. Even when away, Aline remained "stuck" to her responsibilities as a main caregiver and organised the major portion of the childcare.

Aline's experience does not meet conventional representations of women - and especially mothers-being sedentary or undertaking mobility as a trailing partner. In her case, the 
couple's dual-career arrangement permitted both of the partners to take or to keep a position based on their own interests. Yet, this arrangement could hardly be defined as egalitarian, and her mobility cannot be analysed as gender neutral: while Aline's husband worked full-time in Switzerland, Aline worked at $80 \%$ and remained the primary caregiver for their two children. However, Aline's employment conditions and the characteristics of the Swiss context also highly influenced these tasks' partition. First, the precariousness of her contract and her very limited prospects to obtain a stable academic position in the near future contrasted with the stability and benefits associated with her husband's open-ended position. This made the couple less likely to displace the entire family to the UK. Additionally, the absence of an affordable full-time day-care system - a characteristic of Switzerland - burdened Aline's caregiving and mobility arrangements. Because her children only benefitted from day-care facilities on a parttime basis, and considering that the couple could not rely on the proximity of relatives to help, Aline constantly tried "to manage $80 \%$ work time over only 3 days" but experienced exhaustion and increased tensions between her family and career involvements. Her experience of mobility was sticky, in the sense that Aline remained socially, materially and emotionally constricted by her Swiss bindings.

\section{Alberto: "From a Research Standpoint, I Did Not Lose Anything"—negotiating stickiness at the margins of career norms}

After completing a master degree in biology in Italy, Alberto enrolled in a doctorate programme in Switzerland. There, he met Anna, a PhD candidate, with whom he has a child. Anna wished to stay in Switzerland and to quit the academic path after completing her thesis to obtain a stable job in French-speaking Switzerland. Alberto initially planned to experiment with transnational mobility but renounced doing so due to his partner's ultimatum: "It was, 'If you leave, we'll part'"

Alberto therefore decided to obtain his first postdoc position in a neighbouring canton. He thought that his lack of protracted stays abroad would jeopardise the next steps of his career. However, he did not feel comfortable following his peers' and hierarchy's advice of faking a sojourn in a nearby country:

[They] told me, "Go to [a nearby French city] for three months, and then get a paper signed stating that you've stayed there a year".

Instead, Alberto and his supervisor adopted several strategies to mitigate his "sedentary" status. He deliberately shifted his research angle within his field to display intellectual flexibility, and he also applied for an Ambizione postdoc fellowship - one of the few national grants for which prior mobility is "desirable but not required"-in a German-speaking Swiss city. According to his supervisor, crossing a linguistic barrier guarantees "a cultural shock", "a foreign shock" much higher than what can be encountered by staying in Paris.

Alberto reckoned that his sedentary profile "did not prevent [him] from anything" scientifically. He described his academic record as very competitive, with publications in Nature and other major journals in his field:

I was able to choose a high-standing university in Switzerland, a high-standing department, and a professor who just received an ERC . . . with unlimited funds. We were able to do whatever we wanted, with the excellent university technological support. . . . From a research standpoint, I did not lose anything. 
However, in accordance with his thesis director's warnings, Alberto's sedentary profile significantly impacted his academic path:

It affected [my chances to get a permanent position] by, let's say, 90-100\%, because, for example, the very fact that I have not been abroad prevented me from applying for European fellowships. So, I wasn't able to apply for Marie Curie's, I couldn't apply for the EMBO, I couldn't apply for the ENA Frontiers, I couldn't apply for the SNF [or] all these fellowships that . . make a CV. . . . The only criterion I was missing was experience abroad, and so, compared to other candidates, I am left with a CV that is very good on the publications side but that lacks independent fellowships.

Alberto appeared critical regarding not only the mobility norm but also the uniformity of the career-assessment system:

[All the research funding agencies follow] the same criteria, so if someone gets slightly off the beaten track ... he loses 10 options at the same time.

At 38 years old, Alberto was very pessimistic about his chances of getting a permanent position. He reluctantly considered taking a managerial job outside the academic world. He also expressed a resentment towards his successive academic employers, which benefit from his prestigious academic achievements, without offering him a stable job in return.

Alberto's story offers another interesting case with to question the dichotomous approach of mobile and immobile. As with Aline, Alberto's peers and supervisor socialised him to the idea that a postdoc experience abroad and for a protracted period was a sine qua non requirement. In this case again, the decision regarding the place of the academic mobility (a European city accessible by flight for Aline and a neighbouring city for Alberto) was not the result of purely professional motives or the pursuit of a scientific development ideal. Rather, it was closely linked to private concerns that challenged the conjugal balance. Alberto's real-life experience nuances the traditional gendered representations of the immobile woman, whose freedom of movement is hampered by her couple or family duties. We can consider Alberto's intra-national mobility was located on the sticky side of the continuum, in the sense that it was performed as a very limited move in space; was constrained by the existence of conjugal attachment; and was compelled by an explicit refusal from his partner, a $\mathrm{PhD}$ holder, to embrace a career bound to geographic relocations. Alberto perceived his decision to stay in Switzerland as an infringement on his career requirements that he made to protect his relationship. His story is a testimony of an international trajectory - he speaks several languages fluently, publishes in prestigious international reviews, has a network abroad and is mobile between Italy and Switzerland and between Romandy Switzerland and Alemannic Switzerland. Nonetheless, his spatial mobility is not defined as such by research institutions. Conversely, his peers' suggestion to bypass the system by faking mobility reveals a relative disconnect between mobility as an "academic qualification" and mobility as an effective practice of relocation abroad.

Here, the normative and institutional dimensions, rather than the geographic and phenomenological ones, truly contributed to Alberto being labelled as sedentary in the specific context of Swiss institutions, which affected his career in concrete terms.

\section{Nicolas: "I'm Sort of Linking It Together"-a stretchy mobility across borders}

Nicolas is a Swiss-Mexican binational. He completed his bachelor's degree in Mexico City, sojourned in Berlin and then registered in a master's degree programme in political economy 
in London. Early on, he envisioned an academic career, a professional environment that he perceived as familiar:

All my family is academics. So, it's the kind of thing that I guess you are socialised into. ... I was not sure that I wanted to stay in academia, but somewhat, I kind of knew that I wanted to earn a $\mathrm{PhD}$.

Yet, his intellectual motivation outweighed his professional projects or ambitions when he decided to submit a single application for a doctorate position in a prestigious institute in German-speaking Switzerland:

I was very interested in South Africa because of how the country's sort of reconstituting itself. . . . In one way, it was just curiosity, and I just figured out that I had to really dedicate some more time if I really wanted to get to have a clue about what is going on there. . . . I was not too worried about exactly what I was going to do or when after [earning my] PhD. I was just really, really interested in sort of learning more about this.

Nicolas frequently flew abroad and combined a quantitative approach with case studies conducted in several European countries, a methodology that begets an intense workload.

Upon completion of his doctorate studies, Nicolas considered heading towards a diplomatic career, but he preferred to apply to a Swiss-German university for a teaching position at $15 \%$ for five years, closely matching his profile. He then quickly obtained funding for two research projects designed with his tutor and contented himself with a half-time contract:

You are never really working for 50\% always. I saw it as an investment, basically. . . . I guess if, at 50 years old, nothing worked out, then probably, yeah, I would have to be able to work a bit with that, [but] as long as things kind of work, then it's fine.

Nicolas reckoned that his experience and international culture, alongside being proficient in eight languages, constituted a significant asset for his employers and allowed him to access his foreign peers' academic literature better. In addition, he stayed in touch with his former tutors, invited his former professor from Mexico to visit him in Switzerland, and participated in a collaboration contract being signed with his home Mexican university.

During the three years following his doctorate studies, Nicolas also carried out fieldwork in India, China, Mexico and Brazil. He favoured protracted stays, ideally lasting several months, to develop solid bonds with private and academic partners and to satisfy him at the personal level:

I'm sort of linking it together, you know. I also want to sort of consolidate languages. ( . . I I mean, I love these countries, and this probably has to do with my background in a way that I always sort of-I was very curious.

For Nicolas, obtaining a stable position remained "an enormous challenge" and simultaneously an "ideal scenario". He did not tie this prospect with any particular country but conceived past and future geographic flexibility first and foremost as enriching for personal and professional matters, despite the existence of organisational and emotional constraints. Moving from one country to another required him to "start from scratch" all over again but also appeared to be closely linked to his personal desire and room for freedom, which he associated with his single status and absence of children. In addition, Nicolas deemed relocations within Europe to be ever easier. 
The researcher gave himself 10 to 15 years to stabilise in the academic world. In the event of failure, he would consider with interest a professional reconversion as a consultant in Asia or in the diplomatic realm.

Nicolas's case is interesting because it offers a rare example in which academic mobility is not presented - at least, partially — as a constraining professional demand in tension with the private sphere but as an opportunity solely motivated by scientific considerations and personal curiosity. Hence, his real-life example somehow matches the institutional discourse.

If Nicolas's profile is close to the institutional vision of the "mobile researcher", driven by his insatiable scientific and intellectual curiosity, I must note here that this ideal "mobile researcher" presents a set of particular characteristics: a single, cosmopolitan and polyglot man socialised in a familial environment who is used to academic norms and travels and who thus has hindsight regarding the career's uncertainty. He did not consider part-time jobs, short-term contracts or the uncertainty of obtaining a stable position within 10 years through the lenses of casualisation.

We can consider Nicolas's experience as located on the "stretchy" side of the continuum. We can suppose that the merging of socio-cultural components (his familial socialisation and his proficiency in several languages), familial ones (an absence of parental responsibilities or dependence on a partner's goodwill), socio-professional ones (skills acquired from constant travel during his formation and his career) and potentially socio-economic ones (his upperclass origin) contributed to his great flexibility in his geographic relocations and his management of career-related uncertainty. In addition, his multiple geographic roots facilitate an extranational (and extra-sectorial) approach of the job market.

\section{Daniela: "As a Couple, You Can Live Away from Each Other without Any Problems"-negotiating stickiness through sectorial mobility}

Daniela is a Swiss national. After obtaining a bachelor's degree in Scotland and a master's in development science in Geneva, she worked for two years on a development project in Asia and often travelled to Latin America for her work. In order to improve her professional profile, Daniela then decided to quit her job in order to pursue a doctorate. She conducted her field thesis in Sri Lanka and simultaneously coordinated a Swiss research project involving Asian, African and Latin American partners.

Daniela gave birth to her second daughter a week after completing her doctorate studies. She soon moved to Brazil with her newborn and her three-year-old elder daughter to take a consular position as scientific director for four years. During this four-year period, Daniela's husband lived in Switzerland and joined his wife and children for a week per month, thanks to his flexible job at an independent architectural firm. According to Daniela, this organisation stemmed from their shared explicit will to consider their two careers as both equally important and to challenge more traditional arrangements in which the "wife stays behind".

Her choice to accept a position in Brazil was driven by her personal curiosity and scientific and professional criteria but also her proactive eagerness to live abroad once again:

I actually had three different offers, and this was the most interesting one in terms of content. I was also interested in living abroad again for a few years. . . . I'm always sort of - I will be in Switzerland, then go away for a few years, then come back for a few years, and then go away again. .. . [The position] had management experience, which I 
wanted. It was still in research in [my field]. It was in Brazil, which was a country I was interested in. So, it just brought together many interesting aspects - it is extremely well paid and a very highly prestigious job, so, yeah, it was just the most interesting opportunity at that time. But it was not . . . I don't have a career plan. . . . I'm just following my interests and wherever they take me.

Daniela reckoned that her family was not a constraint or a concern when she decided to move to Brazil, especially since her high income allowed her to bear the costs of the required adjustments and the regular flight tickets. However, family management was an important factor that led her to favour a job outside academia at first, despite her wish to continue a university career at the time. On the one hand, she pointed out how her experience as a mother restricted her number of publications and, ergo, her chances to make a career in that field: "Twice when I had to publish, I had a baby twice". On the other hand, she deemed the wage associated with a postdoctorate project to be insufficient to afford a dual-career long-distance relationship.

Going abroad with the Swiss National Science Foundation postdocs is not an option because my husband couldn't follow me. Not in these terms, anyway. . . . Because [the post-doc] would have been in the US, and if you are a postdoc, you get paid very little by the SNF. Whereas in Brazil, I was highly paid, and my husband was able to come much more often".

After four years of intense and "challenging" professional commitments and regularly flying within Brazil, Daniela accepted her hierarchy's offer to hold a similar position in Chicago in the USA. However, at about the same time, she heard about a very attractive academic job in her home country. The idea of returning to her Swiss town, where the couple owns property, and of quitting life "as a global family" appealed to Daniela. Yet, her "first choice" initially was to honour her new contract in Chicago, about which she was enthusiastic. Eventually, her personal intellectual, professional and scientific interests pushed her to renounce the US project to hold a position in her home university. The wage was lower, but the content appeared "closest to [her] passion":

I felt "okay I go to Chicago for four years and then I come back", but then I thought this sort of position probably won't open again exactly at the moment I want to come back to Switzerland. And the content of this work is really what I'm interested in most.

According to Daniela, international mobility "has never been anything but an asset" on the personal and professional levels. The repeated relocations appeared to her as "easier and easier", and her children's schooling in bilingual schools was simple and satisfying. Her stays in different countries and universities abroad enabled her to be proficient in four languages and to "broaden her horizons", but also to develop human and technical skillsets valued in the business world:

It means [you are] not complicated, [you take] initiative, [and are] open to going out of [your] comfort zone, so implicitly that shows in your CV.

During the interview, Daniela did not mention and personal or conjugal price to mobility. She only perceived distance from her husband as a constraint that did not pressure the couple but the children: 
As a couple, you can [live 10 hours away from each other] without any problem for many years . . . but for the kids, it's difficult. My daughter was not even one when we left.

Daniela's trajectory gives a detailed account of the fact that care and family factors should not be conceived as a single analytical framework with which to understand people's trajectories across or outside academic borders. Many other parameters coexist and influence one's decisions. In this case, Daniela's mobility stickiness was contingent more on work conditions (in terms of recognition, prospect, stability and financial resources contributing to stretching the move) than on domestic matters. Daniela wished to continue her trajectory in academia after obtaining her $\mathrm{PhD}$, but she renounced her postdoc mobility project. As epitomised by her relocation to a demanding position in Brazil after her professional conversion to a new path, the very idea of relocating, leaving a partner or combining work with family responsibilities did not come into the equation when she decided to avoid her academic mobility and quit research. Instead, her resignation from academia was based on a pragmatic assessment of the opportunities, working conditions and rewards she could expect from the "outside" as compared to the "inside" world. Finally, Daniela experienced her successive relocations as an ever-easier process, emphasising how the sticky character of mobility evolves across time and space.

The transnational resources they gained from having earned degrees in various countries, mastered several languages and worked on various continents and with transnational collaborators made both Daniela and Nicolas contemplate additional stays abroad with equanimity.

\section{Discussion}

\section{Mobility as an ambivalent and plural professional experience}

The empirical results show the necessity of nuancing institutional, romanticised narratives of academic mobility that portray it as a disembodied, seamless journey. While the interviewees frequently paired their mobility experiences with a range of positive aspects or outcomes, they also highlighted a range of social, financial and emotional costs for them or their relatives. Among the GARCIA/POCARIM sample, most of the participants reported ambivalent experiences of mobility, showed some level of struggles associated with their academic moves and pointed out how mobility may come hand to hand with insecurity rather than self-development, isolation rather than collaboration and exclusion rather than opportunities. The case studies of Aline, Alberto and Daniela shed light on the plural impacts of relocations across academic borders, which are also - to various extents - sticky, creating a set of strings between two locations and reconfiguring bindings.

The results question the often unchallenged adequation between mobility and professional development. The cases of Alberto and Aline highlight the gap that may exist between institutional representations of excellence in the Swiss context-which automatically tend to associate extended postdoctoral mobility abroad with particular competencies such as having a large network, co-authoring articles with international colleagues and learning new methodologies - and the actual scientific value of their journey. Mobility did 
not appear as a guarantee of the two researchers' scientific development per se. Although he did not go abroad after earning his $\mathrm{PhD}$, Alberto thrived scientifically and was able to develop international collaborations. However, this was not the case for Aline, who bitterly paid the high cost of her mobility in her private life without benefits to her scientific development.

Conversely, sticky mobility arrangements such as frequent commuting may constitute a "third shift" that develops at the expense of the researcher's scientific progress. It also provides insights on how postdoc researchers who are unwilling or unable to relocate may build similar competencies easily via other means. This observation is in line with the work of Bernela and Milard (2016), who emphasised that an extended stay abroad may not stimulate co-authorship more than other international experiences would (such as short-term moves and spurring relational chains).

\section{They were all mobile, yet they were all immobile (and reciprocally): questioning the mobile/immobile dichotomy paradigm}

Institutional discourses and an entire section of academic studies alike commonly use a dualist categorisation of mobility based on a distinctive epistemology opposing a "mobile" group to another group that is not. Yet, one striking finding among the 65 interviews was how much mobility was a common, generalised component of the trajectories, for both men and women alike. As for Aline, Alberto, Nicolas and Daniela, these interviewees did cross geographical borders, for research purposes, collaboration, fieldwork, and conferences and for short or longer stays.

Focusing on case studies and adopting a biographical approach helped to uncover the complex realities behind the sparse categories of "mobile" vs "immobile" scholars. Through the case of Alberto, I show how academics who studied or worked abroad, relocating several times across national borders and linguistic areas, were repeatedly involved in international events or far-off fieldwork, yet they identified themselves as "not mobile" in reference to the Swiss academic standards. Reciprocally, the insistent advice from Alberto's peers and advisor to feign a long stay abroad also showed the relative disconnect between institutional categories of "being mobile" and its more geographical, temporo-spatial dimension. While the four interviewees may be defined as mobile in empirical or geographical terms, none of them would clearly tick the box of "being mobile" according to the criteria to which they were most often socialised by institutional actors, supervisors, SNF officers and peers.

Not only was the distinction between mobile and immobile largely disconnected from reallife experiences, but the labelling of the immobile vs the mobile also raises significant stakes since being labelled as immobile was taken as a grounds for academic exclusion. Indeed, the cases of Alberto and Aline clearly illustrate how the - academically and nationally useddefinition of academic mobility may have very concrete and significant consequences on one's chances to compete for academic resources (such as research grants), grow professionally or seek career advancement.

These results highlight the need to develop analytical tools with which to study mobility outside of institutional categories. Stepping away from these dualistic, romanticised institutional categories of mobility using the alternative concept of stickiness allowed me to shed light on the ambivalent facet of mobility and its normative - and potentially excludingdimensions. 


\section{Being a mobile academic in Switzerland: a cross-disciplinary yet paradoxical career norm}

Despite being in different scientific fields, Alberto, Daniela and Aline received similar incentives to go abroad. They encountered a range of discourses (what institutional actors expect from them), practices (what more advanced peers usually do) and rules (what the institution requires from them), which contributed to shaping their understanding of an academic career.

The notion of a "career script" (Laudel et al., 2019) may be used here to understand how ${ }^{1}$ is understood and enacted at both the institutional and individual levels. Laudel et al. (2019) defined a "career script" as a collective representation of what "needs to be done" in order to have a successful academic career. Thus, SNF grant-application guidelines and careerinformation programmes as well as peer-to-peer and supervising relationships became some of the socialisation spaces through which these interviewees built a global knowledge of career norms in their field and a specific representation of what "being mobile" covers, from an institutional standpoint. It includes going abroad after earning a $\mathrm{PhD}$, for one year or more, at a research institution, to a particular group of - mostly Western - destinations, etc.

In opposition to studies showing that the requirement for a postdoc position abroad varies across fields in the German (Laudel et al., 2019) and Dutch (Herschberg et al., 2018) contexts, I show that in Swiss academia, the expectation of mobility mostly has become a career norm enacted - and sometimes subverted - across disciplines. Alberto gave an account of subverting his mobility requirement with a mentor's help. The choice of performing a trans-linguistic yet intra-national mobility allowed him to develop productive, fulfilling research but limited his opportunity to obtain grants, a compulsory step for gaining independence and remaining competitive in a very tight academic market. If going off the beaten track is perceived as a weakness, then academics paradoxically saw abiding by the norm as not being a better guarantee of future results. In a context of fierce competition for scarce positions, Daniela and Aline thus considered, as soon as their $\mathrm{PhD}$ studies ended, that following institutional requirements would still leave them with little to no hope of reaching stable employment in academia.

\section{Mobility as a spectre for women? Considerations in disentangling (im)mobility and gender}

The cases of Daniela, who worked $7000 \mathrm{~km}$ away from her husband, and Aline, a longdistance commuter, among other cases from the POCARIM and GARCIA research projects, illustrate the need to go beyond the common representations of women's mobility. In accordance with the scarce parallel data tracking of men's and women's mobility (European Commission, 2016; Goastellec, 2016), the POCARIM and GARCIA figures enable one to rethink the supposed "women's immobility" within the Swiss context as the persistence of an essentialist epistemology overlapping a "mobile duality" (to be or not to be "mobile") and a gendered one (to be a man or a woman). While these results demonstrate that immobility is not a "female issue" in the Swiss case, the question of how people experience mobility in a given context cannot be addressed without a gender analysis. By stepping away from a strictly dichotomous understanding of mobility, the alternative concept of mobility stickiness offers an essential tool with which to rethink mobility less as one's qualifications - considering mobility as a qualification or as an individual characteristic of being or not being is a common approach 
in the institutional realm - than as an ever-changing experience continuum, at the crossroads of professional, personal and societal constraints and resources.

Through the four case studies, we saw more specifically how both family situations and gender arrangements played important roles in making one's academic mobility a stickier or stretchier journey and how these factors interacted with career moves and professional considerations. Living "together apart" from one's spouse or children, commuting for long hours, asking one's partner to quit his or her position and-among the other GARCIA and POCARIM interviewees - postponing a pregnancy or ending a relationship were all among the common modalities encountered when the interviewees articulated their professional mobility requirements given considerations of private arrangements. While women were mobile, their mobility tended to have higher emotional, social, financial and organisational costs, reflecting and reproducing disadvantages and gender inequalities at stake in the household, within the academic system, and beyond. Previous studies have pointed out the significance of considering dual-career dimensions and other family components in institutional policies aimed at diversifying the academic workforce (Tzanakou, 2017).

Yet, Henderson (2020) also points out the danger of using "care" or "family responsibilities" as "a shorthand or explanatory factor" for the gendered mobility of women attending conferences abroad. Following her observation, I underline how institutions are tempted to approach women's immobility mostly as a work-life balance issue or a care-related dilemma, without unfolding how these dimensions intersect. Hence, institutional analyses resort to shortcuts that "explain" gendered mobilities in a way that reproduces the issue. The case of Daniela, a researcher who renounced the constraints of a postdoc position in the USA to undertake a mobility outside academia but even further away from her partner, reveals the need to deconstruct what I call the primacy of explanatory care - that is, the tendency in institutional academic discourses to point out and address the "mobility problem" or other career equality issues, primarily via a reading grid staging the conflict as being between career and domestic responsibilities. I argue that such a framing, even when critical of the mobility requirement and its potentially discriminatory dimensions, tends to minimise the mobility issue as a work/private life conflict. Moreover, it constitutes a shortcut that confines this conflict to the feminine side. Yet, as shown by Alberto's case, at a time when dual careers or equalitarian couple arrangements are becoming become more frequent, the "mobility problem" is not limited to women's academic careers. On the second hand, it tends to conceal other explanatory reading grids of what makes mobility an issue. In particular, it masks an institutionalising reading grid in which the institutions generate the issue, rather than an individualising reading grid in which the individuals and their home limitations engineer the problem.

\section{From the Peregrinate Academicus to the geoccasional worker: mobility as a precariousness issue}

Daniela's trajectory provided a detailed account on the fact that family factors should not be conceived as a single analytical framework with which to understand people's trajectories across or outside academic borders. After obtaining her $\mathrm{PhD}$, Daniela wished to continue her trajectory in academia, yet she renounced her academic mobility project. We saw that in Daniela's case, the idea of relocating or leaving a partner did not play any role in her decision to avoid academic mobility and quit academia. Instead, her resignation from academia was based on a pragmatic assessment of the opportunities, working conditions and rewards she may expect on the "outside" as compared to the "inside". Trajectories like Daniela's deeply 
question stereotypical assumptions that women, especially mothers, avoid or renounce mobility due to conflicting family responsibilities. They also raise concerns about how the academic system fails to attract academics who are determined to find a reasonable work-life balance and prospects for future upward mobility, in exchange for high levels of flexibility and commitment. Daniela offers a prototypical case with which to nuance the common understanding that the academic mobility problem comes down to a female work-life balance problem.

Alternatively, I introduce the innovative figure of the geoccasional worker to shed light on precariousness as an important explanatory factor with which to understand (and address) mobility issues. Aline's mobility experience is prototypical of what I call geoccasional work. The overlapping and interdependencies between two specific components of professional employment-having to be mobile while working under precarious, uncertain work conditions - generate a specific, structurally induced grounds for vulnerability. In a context in which this vulnerability is not counterbalanced by significant extra-professional resources (for example, having a "portable" spouse, a partner or relative who takes charge of most of the family care, or access to affordable day-care facilities), Aline's mobility coincided with unsustainable tensions between her family and career involvements, and with personal, professional and health costs to her.

In contrast, Daniela's case highlights how economic resources, access to affordable childcare and a favourable couple arrangement participate in easing relocation. In Nicolas's case, the absence of family ties and his privileged familial background were resources allowing him to consider a decade of casual part-time work and future relocations with relative peace of mind. Earning degrees in various countries, mastering several languages and working on various continents and with transnational collaborators appeared as accumulated transnational resources that made both Daniela and Nicolas contemplate additional stays abroad with equanimity.

\section{Conclusion}

In this study, I respond to a call for a better understanding of hidden mobility experiences (Morley et al., 2018) in situated national contexts by focusing on the specific case of Swiss academia. The findings raise questions about the relevance of using traditional dichotomies opposing "mobile" researchers to their "immobile" counterparts. When mobility becomes a normalised phenomenon, then adopting a micro, integrative approach allows for a better understanding of early-career academics' strategies and experiences across institutions and countries. In addition, it permits one to decipher how such strategies are related to specificnationally situated - institutional definitions of what it means to be a "mobile scholar". Finally, it also enables us to identify some of the underlying factors that make academic mobilities stickier or stretchier journeys during the postdoctoral phase.

In the first place, the results suggest that mobility experiences inherently are related to the institutional academic environment in which they occur and from which they stem. In Switzerland, an international academic system that actively fosters migration, mobility is defined at the institutional level by a limited set of very specific practices related to its temporality, destination, duration and purpose. Such mobility appears as a part of a "career script", a collective representation of the basic standards that all early-career researchers must achieve, regardless of the scientific field to which they belong. Understanding how such specific forms of mobility collectively are valued in the Swiss career system is necessary to 
unravel the paradoxical, highly transnational trajectories perceived as "sedentary" in Swiss academia.

Incidentally, I challenge romanticised narratives of mobility that display a fluid and disembodied process allowing individuals to move seamlessly throughout the global academic North. I also explore how mobility is sticky, creating new career borders and barriers, challenging social ties and bodies and affecting not only the scientists but also the network of relatives connected to them.

Finally, I nuance the labelling of mobility as being a "women's issue", a rather common notion in informal - and sometimes even formal - institutional spaces. In line with recent studies (European Commission, 2016; Goastellec, 2016) that question the existence of a universal "mobility gap" between female and male researchers, ${ }^{7}$ I show that being a woman in the Swiss system did not translate per se into renouncing mobility plans or even making one's move a sticky one. Instead, I carefully unknot some of the gendered factors hindering mobility and explore how these parameters interact with other social, environmental and employment-related characteristics. I thus describe specific arrangements in which being a woman — or sometimes a man — becomes a disadvantage. Having a partner who is only mildly committed to equal career arrangements ${ }^{8}$ or who is unwilling or unable to follow, being the main caregiver for children or relatives and having insufficient financial or social resources to delegate childcare or to compensate for the loss of stability or social security benefits that comes with crossing borders were only some of the cumulative factors in favour of a stickier, gendered mobility. The case studies illustrate the contradictions and complexity in gender configurations as academics circulate across countries. The framing of sedentariness as a female issue historically has offered levers of action with which to address inequalities at an institutional level. Yet, female academics hardly may be considered as a homogeneous group. In the case of mobility, I highlight the multiplicity of intersecting factors - from social to institutional and environmental conditions - that participate in shaping stickier or stretchier experiences of mobility across borders.

Many of the standpoints and questions raised in this research may be of future interest to ensure that researchers express their full academic potential regardless of their gender and private situation. That is, the high levels of female and male mobility in the highly internationalised contemporary Swiss context and the sticky experiences of mobility can be considered as both an issue related to the casualisation of academic work and as an equality challenge.

Acknowledgements This paper was originally presented in a symposium at the Meeting of the Society for Research in Higher Education (SRHE, Newport, 2017). I thank Charikleia Tzanakou and Emily Henderson, the convenors of the symposium and editors of this special issue for their inspiration, feedback and support.

The qualitative data analysed in this article were collected within the GARCIA and the POCARIM EU projects. I am particularly grateful to Nicky Le Feuvre, leader of the Swiss section of the GARCIA project, for her continuous support, and also wish to thank Dominique Vinck, co-leader of the Swiss section of the POCARIM project, who granted me access to the data. Special thanks to Pierre Bataille, Maria del Rio Carral, Farinaz Fassa, Gaële Goastellec, Sabine Kradolfer, Soraya Ksontini, Michael Posse, Mélody Pralong, members of the GARCIA team, as well as Lucie Haye, for her precious and meticulous editorial work.

\footnotetext{
${ }^{7}$ The gap between men and women may largely differ across national contexts. In Switzerland, women are as likely to undertake mobility as men are (European Commission 2018).

${ }^{8}$ See on this specific issue the work of Mancini et al. (2019)
} 
I finally thank the NCCR-LIVES and the Institute of Social Sciences for their financial support and extend my gratitude to the anonymous reviewers of Higher Education for their particularly constructive and helpful comments.

Funding This publication benefited from the support of the Swiss National Centre of Competence in Research LIVES (Overcoming vulnerability: Life course perspectives) and the Swiss National Science Foundation. The data analysis was originally conducted within the GARCIA project, funded by the European Union's Seventh Framework Programme (FP7/2007-2013, grant agreement n611737). Open Access funding provided by Université de Lausanne.

\section{Declarations}

Conflict of interest The author declares no competing interests.

Open Access This article is licensed under a Creative Commons Attribution 4.0 International License, which permits use, sharing, adaptation, distribution and reproduction in any medium or format, as long as you give appropriate credit to the original author(s) and the source, provide a link to the Creative Commons licence, and indicate if changes were made. The images or other third party material in this article are included in the article's Creative Commons licence, unless indicated otherwise in a credit line to the material. If material is not included in the article's Creative Commons licence and your intended use is not permitted by statutory regulation or exceeds the permitted use, you will need to obtain permission directly from the copyright holder. To view a copy of this licence, visit http://creativecommons.org/licenses/by/4.0/.

\section{References}

Ackers, L. (2005). Moving people and knowledge: Scientific mobility in the European Union. International Migration, 43(5), 99-131.

Afonso, A. (2016). Varieties of academic labor markets in Europe. Political Science \& Politics, 49(04), 816-821. https://doi.org/10.1017/S1049096516001505.

Appelt, S., van Beuzekom, B., Galindo-Rueda, F., \& de Pinho, R. (2015). Which factors influence the international mobility of research scientists? (p. 1-31) [OECD Science, Technology and Industry Working Papers 2015/02, OECD Publishing].

Bataille, P., \& Sautier, M. (2019). Ce « qu'être postdoc » veut dire. Cheminements postdoctoraux en Suisse, circa 2010. Philosophia Scientae, 23-3, 35-66. https://doi.org/10.4000/philosophiascientiae.2048.

Bataille, P., Le Feuvre, N., \& Kradolfer, S. (2017). Should I stay or should I go? The effects of precariousness on career aspirations of postdocs in Switzerland. European Educational Research Journal, 16(2-3), 313-331.

Béguin, O. (2004). L'Auberge Espagnole: Interculturalism in the European Melting Pot. In D. Powell \& F. Sze (Eds.), Interculturalism: Exploring Critical Issues. Inter-Disciplinary Press.

Bernela, B., \& Milard, B. (2016). Co-authorship network dynamics and geographical trajectories_-What part does mobility play? Bulletin of Sociological Methodology/Bulletin de Méthodologie Sociologique, 131(1), 5-24. https://doi.org/10.1177/0759106316642705.

Bologna Follow-Up Group (BFUG). (2009). The Bologna process 2020: The European higher education area in the new decade. Communiqué of the Conference of European Ministers Responsible for Higher Education.

Conseil d'Etat. (2010). Stratégie internationale de la Suisse dans le domaine formation, recherche et innovation (30.06.2010).

De Ridder-Symoens, H. (ed.). (1996). A history of the university in Europe. Volume 1-Universities in the early modern Europe. Cambridge University Press.

Directorate General for Research and Innovation. (2018). She figures. European Commission.

Enders, J., \& Musselin, C. (2008). Back to the future? The Academic Professions in the 21st Century. Higher Education, 2030(1), 125-150. https://doi.org/10.1787/9789264040663-5-en.

Engel, C. (2010). The impact of Erasmus mobility on the professional career: Empirical results of international studies on temporary student and teaching staff mobility. Belgeo. Revue Belge de Géographie, 4, 351-363. https://doi.org/10.4000/belgeo.6399.

European Commission. (2012). A reinforced European Research Area partnership for excellence and growth. 
European Commission. (2016). She Figures 2015-Gender in Research and Innovation. https://data.europa.eu/ euodp/en/data/dataset/she-figures-2015-gender-in-research-and-innovation.

European Commission. (2017). Modernisation de l'enseignement supérieur en Europe: Personnel académique2017. Rapport Eurydice. EACEA, Analyse des politiques en matière d'éducation et de jeunesse.

European Commission/EACEA/Eurydice. (2018). The European Higher Education Area in 2018: Bologna Process Implementation Report. Publications Office of the European Union.

European Parliament. (2015). Internationalisation of Higher education (Directorate-general for internal policies, p. 304).

Fernandez-Zubieta, A., Geuna, A., \& Lawson, C. (2015). What do we know of the mobility of research scientists and impact on scientific production. In Global Mobility of Research Scientists (Academic Press). Elsevier.

Franzoni, C., Scellato, G., \& Stephan, P. (2012). Foreign-born scientists: Mobility patterns for 16 countries. Nature Biotechnology, 30(12), 1250-1253. https://doi.org/10.1038/nbt.2449.

Geuna, A. (Éd.). (2015). Global mobility of research scientists: The economics of who goes where and why. In Global mobility of research scientists. The Economics of Who Goes Where and Why (Academic Press). Elsevier.

Glaser, B. G., \& Strauss, A. L. (1967). The Discovery of grounded theory: Strategies for qualitative research. Aldine.

Goastellec, G. (2016). La mobilité internationale: une qualité des carrières et des marchés académiques en Europe? Journal of international Mobility, 4(1), 171-188.

Henderson, E. F. (2020). Sticky care and conference travel: Unpacking care as an explanatory factor for gendered academic immobility. Higher Education. https://doi.org/10.1007/s10734-020-00550-1.

Herschberg, C., Benschop, Y., \& van den Brink, M. (2018). Selecting early-career researchers: The influence of discourses of internationalisation and excellence on formal and applied selection criteria in academia. Higher Education, 76(5), 807-825. https://doi.org/10.1007/s10734-018-0237-2.

Hinder, S., Greehalgh, T. (2012). "This does my head in”. Ethnographic study of self-management by people with diabetes.BMC Health Services Research, https://doi.org/10.1186/1472-6963-12-83.

Jepsen, D. M., Sun, J. J.-M., Budhwar, P. S., Klehe, U.-C., Krausert, A., Raghuram, S., \& Valcour, M. (2014). International academic careers: Personal reflections. The International Journal of Human Resource Management, 25(10), 1309-1326. https://doi.org/10.1080/09585192.2013.870307.

Laudel, G., Bielick, J., \& Gläser, J. (2019). 'Ultimately the question always is: "What do I have to do to do it right?"' Scripts as explanatory factors of career decisions. Human Relations, 72(5), 932-961. https://doi.org/ 10.1177/0018726718786550.

Le Feuvre, N., Bataille, P., \& Sautier, M. (2020). Probationary or second-class citizens? Postdoctoral experiences in the Swiss context. In S. Sumer (Ed.), Gendered academic citizenship: Experiences and challenges. Palgrave.

Mancini-Vonlanthen, N., Le Feuvre, N, Davoine, E. (2019). Couple-based self-initiated expatriation: An opportunity or hazard for highly-qualified women? Paper presented to the LIVES IP6 Seminar, Lausanne: Lausanne University, May 28.

Marginson, S., \& Wende, M. van der. (2009). Europeanisation, international rankings and faculty mobility. 109-144. https://doi.org/10.1787/9789264075375-6-en.

Morley, L., Alexiadou, N., Garaz, S., González-Monteagudo, J., \& Taba, M. (2018). Internationalisation and migrant academics: The hidden narratives of mobility. Higher Education, 1-18. https://doi.org/10.1007/ s10734-017-0224-z

Moussaoui, A. (2012). Observer en anthropologie: Immersion et distance. Contraste, 36(1), 29-46.

O'Keefe, T., \& Courtois, A. (2019). 'Not one of the family': Gender and precarious work in the neoliberal university. Gender, Work and Organization. https://doi.org/10.1111/gwao.12346.

Office fédéral de la statistique. (2018). Facilitateurs et entraves à la carrière académique des docteurs diplômés en 2012. Office fédéral de la statistique. https://www.bfs.admin.ch/bfs/fr/home/statistiques/cataloguesbanques-donnees/publications.assetdetail.6146030.html.

Pustelnikovaite, T. (2020). Locked out, locked in and stuck: Exploring migrant academics' experiences of moving to the UK. Higher Education. https://doi.org/10.1007/s10734-020-00640-0.

Rectors' Conference of the Swiss Universities. (2014). Planification stratSwiss Universities statistiques/ catalogue.

Richardson, J., \& Zikic, J. (2007). The darker side of an international academic career. Career Development International. https://doi.org/10.1108/13620430710733640.

Robertson, S. L. (2010). Critical response to special section: International academic mobility. Discourse: Studies in the Cultural Politics of Education, 31(5), 641-647. https://doi.org/10.1080/01596306.2010.516945.

Sautier, M. (2021). Be excellent, be mobile. Mobility as a career script in the Swiss academic system.

Schaer, M. (2021). Mobility and academic precarity (chapitre 6). Doctoral Thesis. 
Swiss National Science Foundation. (2015). Programme pluriannuel 2017-2020, Planification à l'attention des autorités fédérales.

Tzanakou, C. (2017). Dual career couples in academia, international mobility and dual career services in Europe. European Educational Research Journal, 16(2-3), 298-312. https://doi.org/10.1177/1474904116683185.

Tzanakou, C., \& Henderson, E. (2018). Stuck and sticky mobile academics: Reconfiguring the im/mobility binary. Proposal for special issue of Higher Education.

Publisher's note Springer Nature remains neutral with regard to jurisdictional claims in published maps and institutional affiliations. 